\title{
A Techno-Economic Comperative Study for Wood and Other Building Materials in Terms of Energy Efficiency
}

\author{
I.Cengiz Yilmaz ${ }^{1, *}$, Deniz Yilmaz ${ }^{2}$ \\ ${ }^{1}$ Istanbul Arel University, Civil Engineering Department, Istanbul Turkey \\ ${ }^{2}$ Istanbul Arel University, Mechanical Engineering Department, Istanbul Turkey
}

\begin{abstract}
.
In order to provide thermal comfort conditions, indoor temperature and humidity values must meet certain standards. The energy consumed must also be considered in order to provide these standard values. One of the most important parameters to provide thermal comfort conditions with as minimum energy consumption as possible is the properties of the building material. Wooden, stone, and masonry which are the main building materials of old Turkish buildings, have an important place in this respect. In this study, a comparison of wooden, stone, and masonry structures, which have almost the same properties and in the same region, were compared in terms of energy efficiency and cost effectiveness. During the summer and winter seasons, temperature, and moisture content of the external and internal surfaces of the building and the heat transfer coefficients of the materials were measured. Also, indoor, and outdoor temperature and humidity data are collected to determine the energy efficiency of the buildings. Besides, seasonal energy consumption of the building was read from the electricity and natural gas meters.
\end{abstract}

Keywords: building cost assessment, energy efficiency, heat transfer, sustainability, wooden structures

\section{Introduction}

The use of wood as a building material dates to ancient times. Its use can be seen at different times and in many parts of the world. It is possible to say that the widespread use of wood and well-preserved early examples can be seen at the traditional residential and religious buildings in Eastern Europe and Middle East from the 12th century. For example, The Seljuk Sultanate coming in 11th century to Anatolia built many mosques, public and military buildings of timber between 12th and 15th centuries (Arun, 2012). 


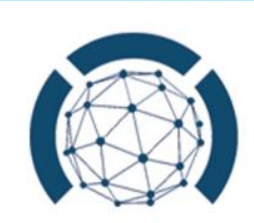

Despite the fact that wood is easily obtained from nature and can be easily applied during construction, the development process of wooden structures from early ages to today's construction systems has been slow. With the influence of the Industrial Revolution in the 19th century, the use of wood in buildings has decreased as a result of the use of new products in the building industry, especially with the widespread use of stone and brick masonry systems, and the introduction of steel and reinforced concrete construction systems.

Despite this superiority of steel and reinforced concrete in terms of fabrication wooden structures offer the healthiest environment to live in with its superior thermal and moisture insulation properties. In fact, there are many studies in literature showing the advantages of structural wood material. For example, Kuzman et al. (2013), stated that wood material will play an important role in the future in terms of energy efficient building methods due to its environmentally friendly and sustainable properties compared to traditional materials. In addition, Asdruali et al (2016), defined wooden materials are sustainable, recyclable, reusable and naturally renewable for today's environment and energy oriented building applications, moreover, its excellent strength-to-weight ratios, thermal insulating and acoustical properties make it useful for different kinds of applications in buildings. Buchanan and Levine (1999) investigated the global impact of wood as a building material by considering emissions of carbon dioxide to the atmosphere and presented that a $17 \%$ increase in wood usage in the New Zealand building industry could result in a $20 \%$ reduction in carbon emissions from the manufacture of all building materials, being a reduction of about 1,5\% of New Zealand's total emissions. They also concluded that the reduction in emissions is mainly a result of using wood in place of brick and aluminium, and to a lesser extent steel and concrete, all of which require much more process energy than wood. Nassen et al. (2011), compared buildings with concrete frames and wooden frames concerning their life-time carbon dioxide emissions as well as their total material, energy and carbon dioxide costs and concluded that wooden frames are advantageous.

However, despite these superior aspects, it is possible to say that wood material is affected by some physical conditions. The hardness, humidity, specific gravity, and thermal conductivity of the wood are very important. Cellulose, which forms the basis of the wood material, is a heat-proof material. However, the conductivity of the heat may differ according to the moisture content, type and fibre direction in the wood material. Especially its moisture and temperature directly affect the mechanical properties of wood. In his study, Fojtik (2018) analyzed how seasonally outdoor temperature and humidity values affect the moisture content of wood material in 17 historical and modern bridges and stated that this change affects the mechanical properties of the material. In many studies like this, it has been stated that the moisture and temperature conditions of the wood changes the mechanical properties of the material. [(Kretschmann, 2010);(Ramage et al., 2017); (Zhou et al. 2015); (Hernandez et al. 2014); (Ozyhar et al., 2012); (Glass et al., 2010) etc.]. 


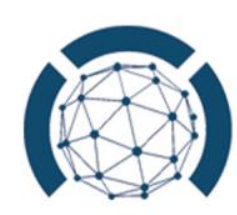

In this study, historical buildings made of three different traditional building materials were selected for measurements. Detailed research has been done about the buildings and the buildings in the same area have been selected to have similar microclimate effects. It was chosen as a mosque so that the buildings selected for the measurement could be of a similar nature. One of the buildings is wooden (Fig.1(a)), one is masonry (Fig.1(b)) and the other is natural stone (Fig.1(c)). The building area of the wooden building is $120 \mathrm{~m}^{2}$, the building area of the reinforced concrete building is $241 \mathrm{~m}^{2}$, and the building area of the stone building is $273 \mathrm{~m}^{2}$.

Figure 1: (a) Wooden mosque (b) Stone mosque (c) Masonry mosque

(a)

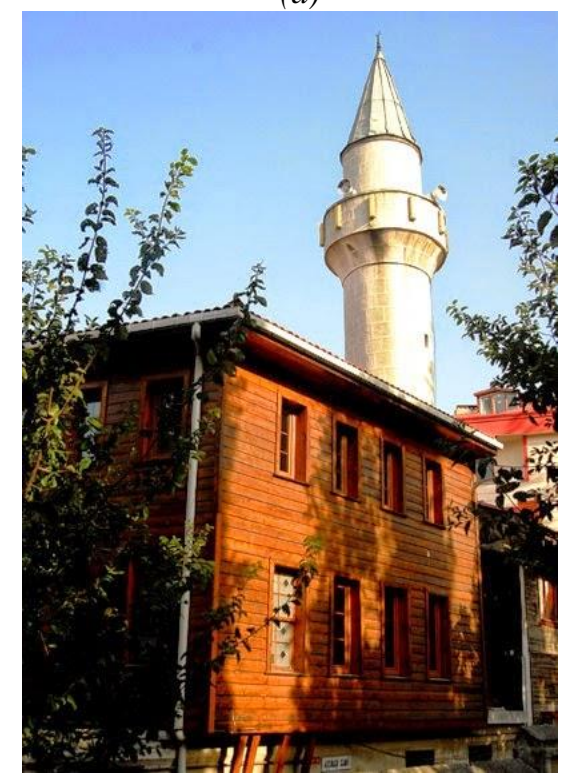

(b)

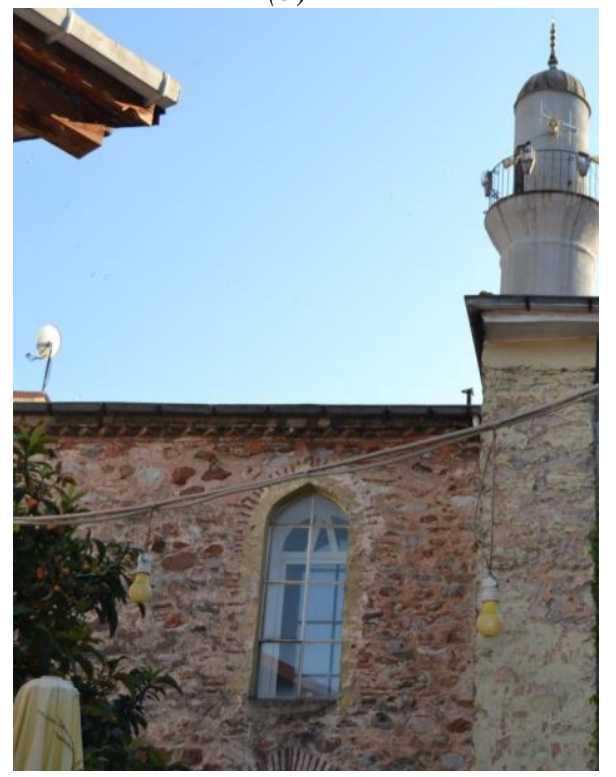

(c)

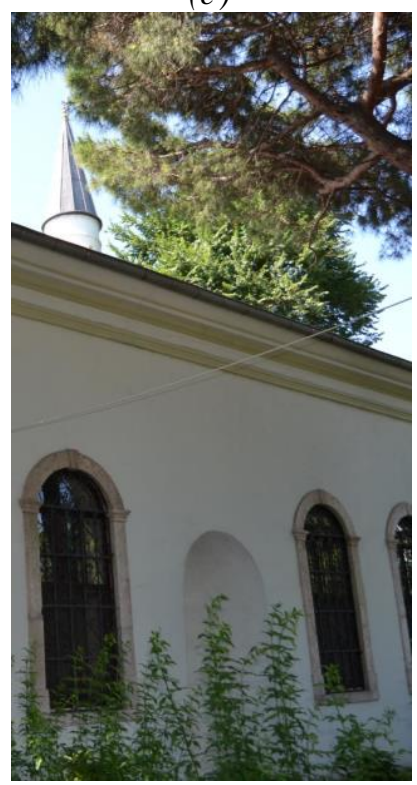

\section{Materials and Methods}

Measurements were taken every two weeks during the summer and winter seasons. The temperature and humidity values of the external and internal surfaces of the building were measured with hand-held measuring instruments that do not damage the building since it is a historical building. Outdoor and indoor environment temperature and relative humidity were measured and recorded with data loggers. For surface moisture measurements, Testo 616 surface moisture device was used (Fig.2 (a)). The heat transfer coefficients of the materials were also measured with Testo 635-2 (Fig.2 (b)). The Testo 174-H datalogger was used to record indoor temperature and relative humidity. NTC sensor sensitivity is $\pm 0.5 \mathrm{C}$, humidity measurement accuracy is $\pm 3 \%$ RH (Fig.2 (c)). Also, to determine the energy efficiency of the buildings, seasonal energy consumption was read from the electricity and natural gas meters. 


\section{$6^{\text {th }}$ International Conference On}

Modern Approaches in SCIENCE,

TECHNOLOGY \& ENGINEERING

\section{8 - 20 September, 2020 \\ MILAN, ITALY}

Figure 2: In-Situ measurements.

(a)

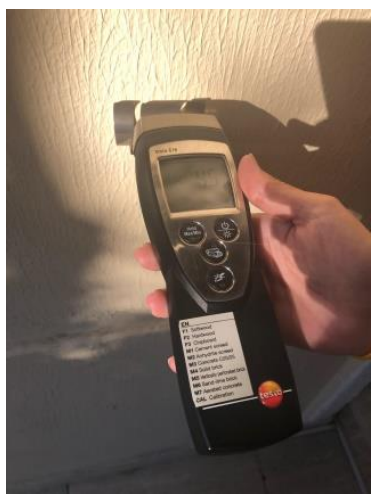

(b)

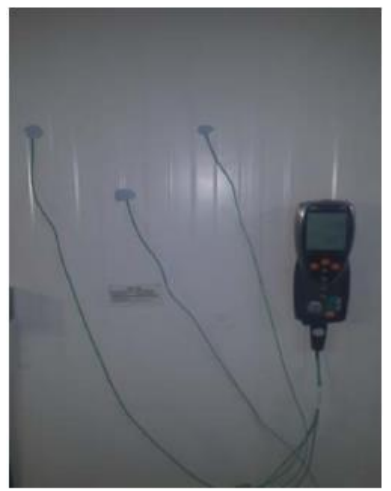

(c)

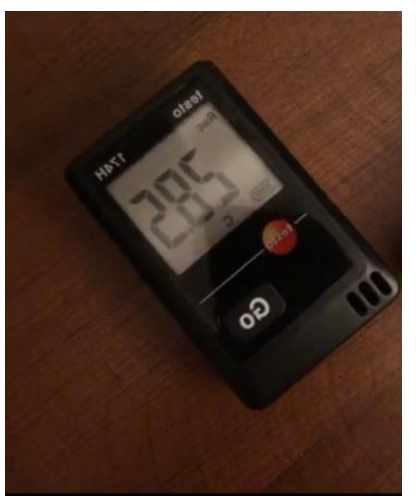

\section{Results}

When the data obtained are examined, the sample graphs explaining the general case are given in Figures 3 and 4 by taking a 50-hour period from all the measured time. Indoor temperature and indoor relative humidity values are presented in Figure 3 and Figure 4, respectively. According to these results, the effect of the outdoor temperature conditions to building made of wood material is less than that of other materials. On the other hand, masonry is heavily affected by the ambient temperature conditions. When we compare these results with the measured thermal conductivity coefficients (See Tab.1), the relationship obtained is significant. In Figure 4, it is seen that the indoor relative humidity changes with time. Due to the structural nature of the wood, the relative humidity values of the indoor environment are high than masonry and stone buildings.

Table 1: Thermal conductivity coefficient.

\begin{tabular}{|l|c|c|c|}
\hline & Wooden Building & Stone Building & Masonry Building \\
\hline $\begin{array}{l}\text { Thermal conductivity } \\
\text { coefficient }\left(\mathrm{Wm}^{-1} \mathrm{~K}^{-1}\right)\end{array}$ & 0.145 & 0.898 & 1.027 \\
\hline
\end{tabular}




\section{$6^{\text {th }}$ International Conference On}

\section{Modern Approaches in SCIENCE,}

TECHNOLOGY \& ENGINEERING

\section{8 - 20 September, 2020 MILAN, ITALY}

Fig. 3: Change of buildings' internal temperatures with time

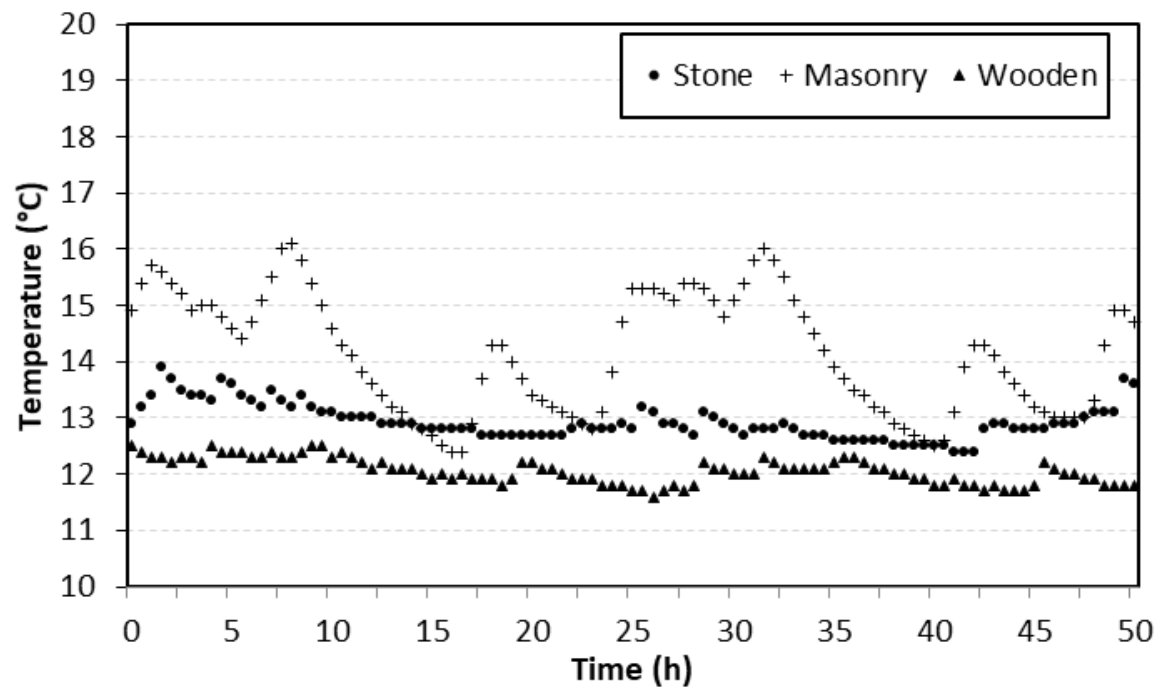

Fig. 4: Change of buildings' internal relative humidity's with time

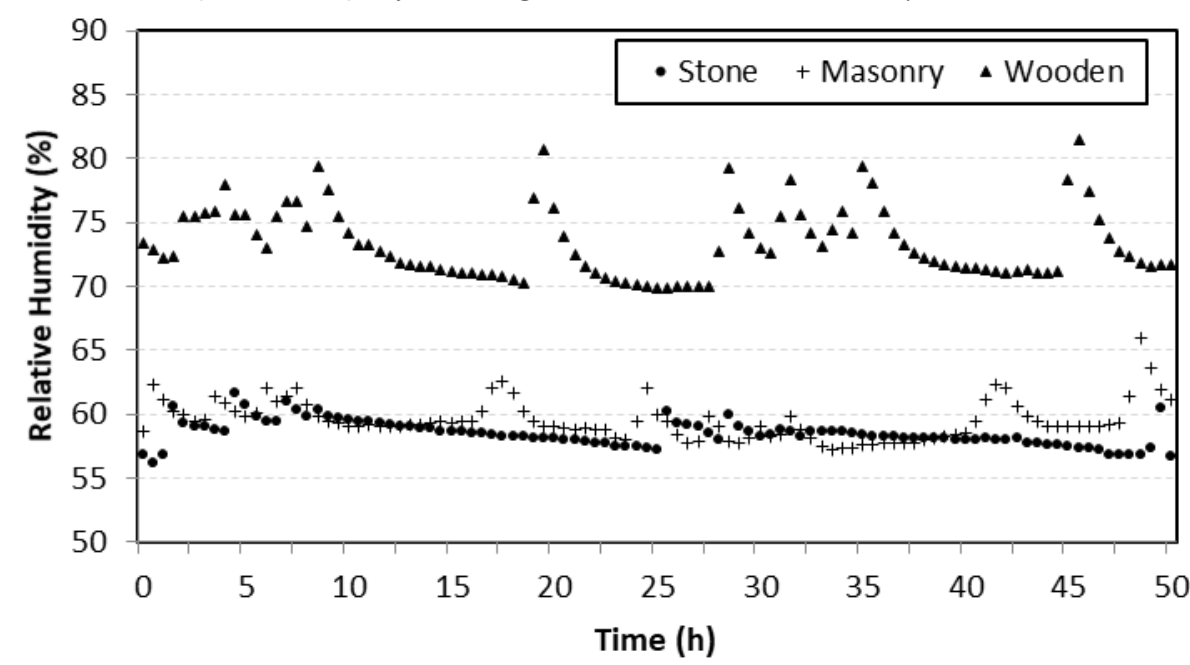

Tab. 2: Average humidity, moisture, and temperature values for sample buildings.

\begin{tabular}{|l|c|c|}
\hline & Average external moisture content (\%) & Average internal moisture content (\%) \\
\hline Stone & 6.05 & 4.84 \\
\hline Masonry & 10.73 & 4.97 \\
\hline Wooden & 4.26 & 4.41 \\
\hline & Average ambient humidity $(\%$ RH) & Average internal humidity $(\%$ RH) \\
\hline Stone & 49.66 & 58.29 \\
\hline Masonry & 52.56 & 59.57 \\
\hline Wooden & 48.89 & 73.1 \\
\hline & Average ambient temperature $\left({ }^{\circ} \mathrm{C}\right)$ & Average internal temperature $\left({ }^{\circ} \mathrm{C}\right)$ \\
\hline Stone & 12.4 & 12.92 \\
\hline Masonry & 10.73 & 14.2 \\
\hline Wooden & 12.04 & 12.13 \\
\hline
\end{tabular}


In addition to these measurements, the energy consumption of each building was measured on site. According to the measurement results, while the energy consumption cost per area of the wooden building is $0.10 €^{-2}$, this value is 0.1840 and 0.3872 for stone and masonry, respectively. Therefore, it can be said that wood material is more efficient and advantageous than the stone and masonry building in terms of energy consumption of the buildings in parallel with the measurements taken and the results obtained.

Tab. 5: Average energy consumptions for structures.

\begin{tabular}{|l|c|c|c|}
\hline Type of Structure & $\begin{array}{c}\text { Energy Consumption } \\
\left(\mathrm{kWhm}^{-2}\right)\end{array}$ & Unit Price $(€)$ & $\begin{array}{c}\text { Total Cost of Energy } \\
\left(€ \mathrm{~m}^{-2}\right)\end{array}$ \\
\hline Wooden & 5.12 & 0.02 & 0.1024 \\
\hline Stone & 9.20 & 0.02 & 0.1840 \\
\hline Masonry & 19.36 & 0.02 & 0.3872 \\
\hline
\end{tabular}

\section{Conclusion}

In terms of energy efficiency and sustainability, the type of material to be selected in the buildings is very important. When considering the conditions of the building to be constructed, not choosing the appropriate material for the type of building brings many losses in terms of techno-economics. In this study, a comparative analysis of traditional building materials such as wood, masonry and stone used in historical buildings built in the mosque concept is given in terms of energy efficiency. As a result of the measurements and the values obtained, the advantageous condition of the wood material over the other two types of material is outstanding. The methodology used in this study can be tested in different types of buildings and different ambient conditions in future studies, and the different effects of conventional building materials can be examined in terms of energy efficiency.

\section{References}

[1] Arun, G. (2012). Evolution Of Timber Construction In Turkey. Archi-Cultural Translations through the Silk Road 2nd International Conference, Mukogawa Women's Univ., Nishinomiya, Japan, July 14-16.

[2] Asdrubali, F., Ferracuti, B., Lombardi, L., Guattari, C., Evangelisti, L., Grazieschi, G. (2017). A review of structural, thermo-physical, acoustical, and environmental properties of wooden materials for building applications. Building and Environment, vol.114, pp.307-332.

[3] Buchanan, A., Levine S. (1999). Wood-based building materials and atmospheric carbon emissions. Environmental Science \& Policy, vol.2, pp.427-437.

[4] Cabeza, L. F., Barreneche, C., Miró, L., Morera, J. M., Bartolí, E., Fernández, A. I. (2013). Low carbon and low embodied energy materials in buildings: A review. Renewable and Sustainable Energy Reviews, vol.23, pp.536-542. 


\section{$6^{\text {th }}$ International Conference On}

\section{Modern Approaches in SCIENCE, TECHNOLOGY \& ENGINEERING \\ 18 - 20 September, 2020 MILAN, ITALY}

[5] Glass, S. V., Zelinka, S. L. 2010. Moisture relations and physical properties of wood. Wood handbook: wood as an engineering material: chapter 4. Centennial ed. General technical report FPL; GTR-190. Madison, WI: US Dept. of Agriculture, Forest Service, Forest Products Laboratory, 190, pp.4-1.

[6] Hernández, R. E., Passarini, L., Koubaa, A. (2014). Effects of temperature and moisture content on selected wood mechanical properties involved in the chipping process. Wood Science and Technology, vol.48(6), pp.1281-1301.

[7] Kretschmann David E., Chapter 5-mechanical properties of wood. In: Woodhandbookwood as an engineering material. Forest products laboratory; 2010, pp.1-46

[8] Kuzman M., Groselj P., Ayrilmis N., Zbasnik-Senegacnik M. (2013). Comparison of passive house construction types using analytic hierarchy process, Energy and Buildings, vol.64, pp.258-263.

[9] Nässén, J., Hedenus, F., Karlsson, S., Holmberg, J. (2012). Concrete vs. wood in buildings-An energy system approach, Building and Environment, vol.51, pp.361-369.

[10] Ozyhar, T., Hering, S., Niemz, P. (2012). Moisture-dependent elastic and strength anisotropy of European beech wood in tension. Journal of Materials Science, vol.47(16), pp.6141-6150.

[11] Ramage, M. H., Burridge, H., Busse-Wicher, M., Fereday, G., Reynolds, T., Shah, D. U., Allwood, J. (2017). The wood from the trees: The use of timber in construction, Renewable and Sustainable Energy Reviews, vol.68, pp.333-359.

[12] Zhou, A., Tam, L. H., Yu, Z., Lau, D. (2015). Effect of moisture on the mechanical properties of CFRP-wood composite: an experimental and atomistic investigation, Composites Part B: Engineering, vol.71, pp.63-73 